\title{
Arterial Hypertension and Physical Activity
}

\section{Karine Zortéa e Rafaela Festugatto Tartari}

Departamento de Psiquiatria do Hospital de Clínicas de Porto Alegre, Hospital Santa Rita do Complexo Hospitalar Santa Casa de Porto Alegre, Porto Alegre, RS - Brazil

\section{Dear editor,}

Borges et al ${ }^{1}$ have stressed that overweight may lead to increased susceptibility to systemic arterial hypertension (SAH), involving primarily sociodemographic factors, diet and smoking. In the population analyzed, $55.7 \%$ of the individuals did not exercise, and no significant associations were observed between physical activity and SAH. [Avaliar ajustes feitos]

It is well known that physical activity may be of help in the treatment of SAH, for its effect on weight control and health promotion. Physical activity, therefore, should be stimulated, as a means to control overweight and prevent diseases.

Silva and Lopes $^{2}$ reported lower prevalence of overweight

\section{Key words}

Hypertension; motor activity; obesity.

\section{References}

1. Borges HP, Cruz NC, Moura EC. Associação entre hipertensão arterial e excesso de peso em adultos, Belém, Pará, 2005. Arq Bras Cardiol. 2008; 91(2): 110-8.

2. Silva KS, Lopes AS. Excesso de peso, pressão arterial e atividade física no deslocamento à escola. Arq Bras Cardiol. 2008; 9 1(2): 93-101. and lower body fat levels among students going to school on foot or by bicycle than in students who were passively transported to the school. The authors observed that a minor change in lifestyle, with an increase in physical activity represented by walking or biking to school, is capable of preventing overweight and increased blood pressure (BP).

Although the mechanisms are not yet completely understood, the regular practice of physical exercise is believed to decrease the levels of serum catecholamines and peripheral vascular resistance, resulting therefore in lower $\mathrm{BP}^{3}$.

The prevalence of sedentariness has not been estimated in Brazil, but it has been repeatedly mentioned as an important risk factor for cardiovascular diseases (CVD). Sedentary individuals have a risk for SAH that is $30 \%$ higher than that of active individuals ${ }^{4}$.

Adopting healthy dietary habits and having regular physical activity should therefore be strongly stimulated among the population, to prevent $\mathrm{SAH}$ and stop the progression of $\mathrm{CVD}$ in our country.

3. Stewart KJ. Exercise and hypertension. In: ACSM's resource manual for guidelines for exercise testing and prescription. USA: William \& Wilkins, 1998. p. 275-87.

4. Fagard RH. Physical activity, physical fitness and the incidence of hypertension. J Hypertens. 2005; 23: 265-7. 


\section{Reply to the Editor's Letter}

\section{Dear Chief Editor,}

It is worth stressing out that the results described by the authors (Zortéa and Tartari, 2009) concerning the survey performed with 7 to 12 year old students in João Pessoa/PB, is relevant (Silva and Lopes, 2008). However, it is important to emphasize that although the associations reveal a lower level of overweight on schoolchildren actively commuting to school, we can hardly know whether this behavior would be enough to reduce body fat. On the other hand, general literature agrees on the fact that children and young people who adopt active behaviors on their daily lives, such as walking or riding from home to school, tend to be more active in other contexts, contributing to increase overall physical activity. In this vein, we may suggest that the physical activity performed while commuting to school may prevent or minimize overweight, avoiding a potential increase of blood pressure early in childhood. Future studies could analyze, through interventions of experiments, the extent to which this domain could effectively contribute to follow recommendations of daily physical activities and control overweight.

Yours Sincerely

Kelly S. Silva 